\title{
COMPARATIVE QUALITY ASSESSMENT OF ROOT CANAL PREPARATION WITH DIFFERENT SYSTEMS OF ENDODONTIC INSTRUMENTS
}

DOI: $10.36740 /$ WLek202006112

\author{
Maryna A. Goray, Nataliia G. Gadzhula, Olena V. Muntian, Olena L. Cherepakha, Larysa F. Kurdysh \\ NATIONAL PIROGOV MEMORIAL MEDICAL UNIVERSITY, VINNYTSIA, UKRAINE
}

\begin{abstract}
The aim: To compare the quality of root canal system preparation with the use of manual K-files, machine Protaper Universal and Silk files by in vitro studies.

Materials and methods: Root canals preparation in 45 extracted premolars was performed in three groups with 15 teeth in each with K-files, Protaper Universal and Silk files. Transverse sections of the dental root were prepared. Histologically were assessed: amount of sawdust and predentin remaining, the purity degree of root canal walls. Results: When calculating the sawdust amount at the distance of $3 \mathrm{~mm}$ from an apex, a high degree of contamination was observed in the manual K-file group: $53.3 \%$ versus $33.3 \%$ in the Protaper Universal group and against $20.0 \%$ in the Silk file group. The amount of predentin after root canal treatment with manual files reached $25-30 \%$. At the distance of $5 \mathrm{~mm}$ from the apex the root canals with high and medium purity degree were detected in $86.7 \%$ with Silk files and $80.0 \%$ with Protaper Universal files used. All predentin was removed when working with Protaper Universal and Silk files.

Conclusions: In the histological sections of the root canals treated with K-files, the larger amount of dentine particles and predentin has been revealed than when using machine tools. The largest amount of predentin and dentine were removed with Protaper Universal files. Silk endodontic system is better for treatment of the root canals dentine surface in the apical area compared to Protaper Universal and K-files.
\end{abstract}

KEY WORDS: root canals, endodontic treatment, K-file, Protaper Universal, Silk

Wiad Lek. 2020;73(6):1145-1148

\section{INTRODUCTION}

Dental health is one of the most important components of the population health, which is largely related to the quality and success in the person's social life [1]. Although endodontics is one of the most developed field of dentistry, the problem of endodontic dental treatment is relevant in Ukraine, as there is no tendency to reduce the prevalence of pulp and apical periodontal diseases [2]. With the development of the dental services, patient demands are increasing, high costs and frequent complications are leading to conflicts and lawsuits. Under such conditions, the search for new effective methods of treatment for endodontic patients is increasingly important.

Proper preparation of the root canal system is an important stage in clinical endodontic practice. The task of the dentist at this stage is to remove the biofilm and smear layer from the root canal system, minimal removal of the parietal dentin, observing the anatomical shape of the root canal during its enlargement and formation, as well as preserving the unaffected dentin as much as possible during the tooth recure $[3,4]$.

Despite the great variety of endodontic instruments, proper preparation of the root canal walls is not achieved in all cases [5]. This is due to the peculiarities of the anatomical and morphological root canals structure in different groups of teeth, the shape of endodontic instruments, the method of their use and the doctor's manual skills. According to numerous clinical studies, in the root canal system, the most accessible area for instrumentation and drug treatment is the apical zone, where $90 \%$ of the root canal orifice open [6].

It is promising to use modern nickel-titanium machine systems that permit proper processing of the root canal apical part, maintain its shape, prevent the apex transportation and removal of infected masses into the periapical tissues, accelerate the dentist's work $[3,5]$. The better formed and cleaned the canal walls are, the more smear layer of dentin and organic residues is removed from it, which significantly affects its sealing $[4,7,8]$. Therefore, it is promising to study the quality of root canal preparation with different systems of endodontic instruments.

\section{THE AIM}

The aim of the study was to compare the quality of root canal system preparation with the use of manual K-files from "Many", machine nickel-titanium Protaper Universal tools from "Dentsply / Maillefer", and Silk files from "Many" by in vitro studies.

\section{MATERIALS AND METHODS}

To achieve this purpose, the preparation of buccal root canals in 45 extracted upper premolars was performed. Palatine root canals were the control. All teeth were main- 
tained in 5.25\% sodium hypochlorite solution for 2 hours, then placed in saline to prevent them from drying and brittleness during preparation. Instrumental processing was performed by a single specialist with the X-Smart endomotor from "Dentsply / Maillefer" according to the "Crown-down" method. Torque and rate of preparation were set according to the manufacturer's recommendations. All teeth were divided into three groups with 15 teeth in each. In the first group of teeth, buccal canals were dissected with manual K-files made of stainless steel by the "Step-back" technique, in the second - Protaper Universal machine files, in the third - Silk machine files were used.

K-file No. 10 was used to determin the working length and patency of the root canals. In all tooth groups, saline was used to eliminate the chemical effects of endodontic agents on the canal wall for irrigation and lubrication. After preparation, the root canal entry was completely closed with glass ionomer cement, $\mathrm{X}$-ray image were obtained. The teeth were then immersed into a $10 \%$ room temperature formalin solution for 24 hours and in a 10\% hydrochloric acid solution for decalcification. To neutralize hydrochloric acid, the teeth were placed in lithium bicarbonate for 5 minutes. Then, transverse sections of the dental root were prepared at a distance of $3 \mathrm{~mm}$ and $5 \mathrm{~mm}$ from the anatomical apex and stained with hematoxylin-eosin solution [9].

$\mathrm{X}$-ray images were studied for the smoothness and fluency of the canal walls contour, maintained root canal anatomical shape, the presence of shoulders in the root canal, maintained apical narrowing. Histological examination was performed on the basis of the Vinnytsia Regional Anatomic Pathology Bureau laboratory. Under the "LOMO" light microscope and Digital Camera for Microscope ScienceLab DCM520 (USB 2.0) Resolution 5.0 $M$ pixels (magnification $\mathrm{x} 40 ; \mathrm{x} 100 ; \mathrm{x} 400$ ) the following parameters were assessed: amount of sawdust and predentine remaining in the root canal after preparation, as well as the purity degree of preparated and control canal walls, lack of organic conglomerates. Infected dentine and pulp residues covering the root canal wall were taken for the sawdust.

To assess the sections, each canal was divided into 4 quadrants according to Maryam Ehsani [9]. Grades 1 to 4 were used to reflect changes in each quadrant: number 1 in the presence of sawdust from 0 to $25 \%$, number 2 - from 26 to $50 \%$, number 3 - from 51 to $75 \%$, number 4 - from 76 to $100 \%$. The presence of dentin sawdust in only one quadrant (up to 25\%) indicates a high degree of root canal wall cleaning, in two quadrants (up to 50\%) - a medium degree, more than two (51-100\%) - low degree.

\section{RESULTS AND DISCUSSION}

The histological structure of the root canal consists of the pulp, a layer of odontoblasts, predentin and dentin with a complex tubular system. In case of the pulp death, the dentinal tubules are dehydrated, microorganisms that localize mainly in the region of the predentin easily migrate into their lumen. To improve long-term results of endodontic treatment, this infected layer should be mechanically re- moved. Figure 1 shows histological sections of a preparated root canal and those of a control untreated canal.

In group I of root canals, preparated by manual K-files, deviations from the anatomical shape of the canal and the presence of shoulders were observed in X-ray images in $26.7 \%$ of cases $(4 / 15)$. The root canal walls were uneven, with furrows in $33.3 \%$ of teeth $(5 / 15)$. In histological examination, the smear layer was preserved around the perimeter of the root canals (fig. 2). In the apical part, organic fibers and dentine sawdust were found. When calculating the sawdust amount at the distance of $3 \mathrm{~mm}$ from the root canal apex, a high degree of contamination was observed in the manual K-file group: $53.3 \%$ (8/15) versus 33.3\% (5/15) in the Protaper Universal group and against 20.0\% (3/15) in the Silk file group (table I). The high degree of the root canals contamination in teeth group I with sawdust, infected dentin and pulp tissue remains further impedes the effective removal of microorganisms from the root canal lumen and non-leaking filling of the apical area.

The amount of predentine after standard root canal treatment with manual files reached $30 \%$ at the distance of $3 \mathrm{~mm}$ and $25 \%$ at the distance of $5 \mathrm{~mm}$ from the apex. Subsequently, the root canal system required more sophisticated methods of cleaning and disinfection. Confirmation of poor root canal walls treatment in the samples of group I is the presence of local parietal oval calcificates, remnants of the pulp vessels, organic fibers at the distance of 3 and $5 \mathrm{~mm}$ from the apical zone (fig. 3).

In group II specimens prepared with Protaper Universal files, the root canal surface was clean and smooth enough. Among the 15 treated teeth, X-ray images of the root canal walls' internal surface revealed single roughs, furrows and shoulders in $26.7 \%$ of cases $(4 / 15)$.

As a result of histological examination of the cross sections in this group of teeth at the distance of $3 \mathrm{~mm}$ from the apex, the degree of the root canals cleaning was uneven: canals with a high cleaning degree were found in $26.7 \%$ of cases (4/15), with a medium degree - in $40.0 \%(6 / 15)$, with a low degree - in $33.3 \%(5 / 15)$. The best indices of machine processing were observed at the distance of $5 \mathrm{~mm}$ from the apical narrowing of the root canals (fig. 1). This is due to the larger diameter of the canal at the distance of $5 \mathrm{~mm}$ from the apex, as well as due to the variable taper of the Protaper Universal files, which improves the removal of dentin sawdust during preparation.

The amount of residual predentin was the lowest after treatment with machine files Protaper Universal: $10 \%$ at the distance of $3 \mathrm{~mm}$ from the apex of the root canal, $0 \%$ at the distance of $5 \mathrm{~mm}$ (table I). In addition to predentin, which was completely removed, significant root canal dentin removal was observed in the individual root canals.

Protaper Universal tools are more aggressive to hard tooth tissues, so it is advisable to use them in the clinic for well patent canals with sufficient volume of parapulpar dentin, namely the palatine and distal molar canals, palatine root canals of the premolars, maxillary cuspids and incisors. Due to the progressive taper of the Protaper Universal tools, the action of each tool is limited to a specific section 


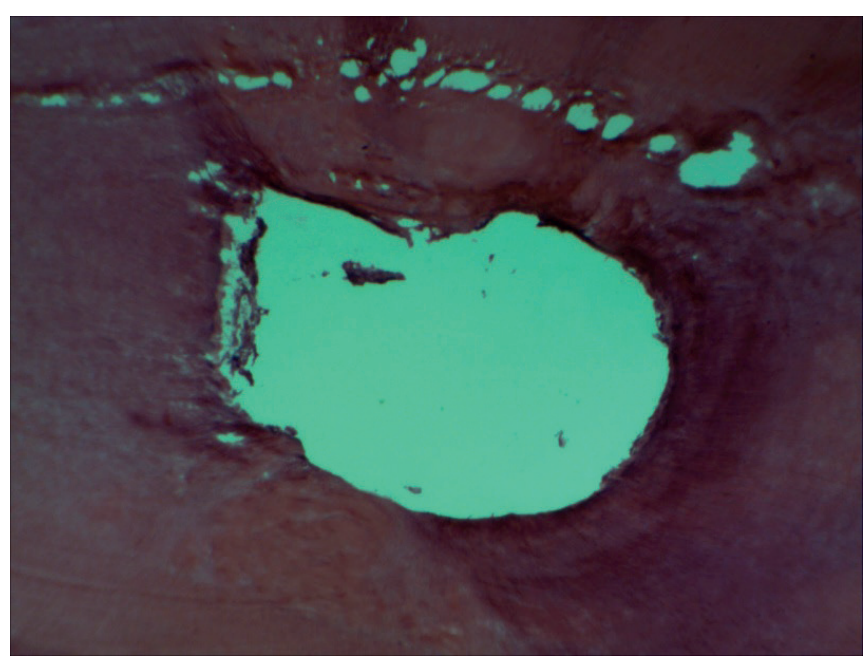

Fig. 1. Histological section of the 14 th tooth roots at the distance of $5 \mathrm{~mm}$ from the apex (x40): to the left - root canal after preparation with Protaper Universal files, to the right - control root canal.

of the root canal, which permits using a shorter sequence to reproduce the shape of the canal according to Schilder.

In the study of group III samples, preparated with Silk files, the root canal walls were smooth, the anatomical shape of the canal was preserved after its formation. Histological assessment of the determined sawdust amount in the samples of this group at the distance of $3 \mathrm{~mm}$ from the apical opening revealed the best quality of preparation compared to the previous groups: sawdust and disorganized root dentine were not detected, although destructed organic fibers were observed (fig. 4). The amount of residual predentin was $15 \%$.

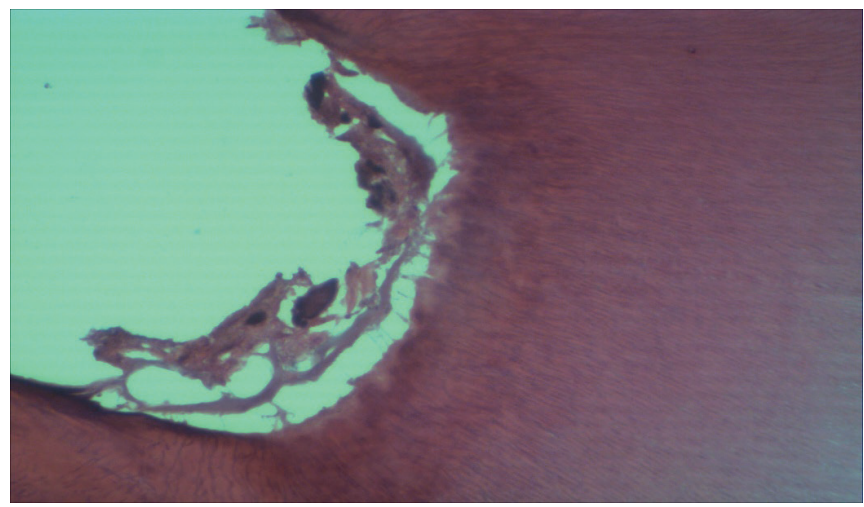

Fig. 3. Histological section of the root canal wall preparated with manual $\mathrm{K}$-files at the distance of $5 \mathrm{~mm}$ from the apex (x400)

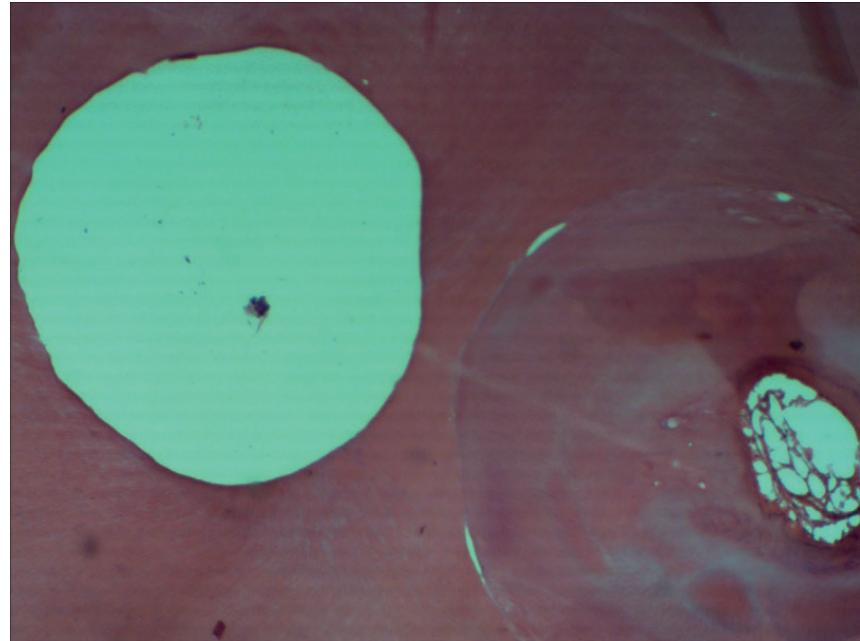

Fig. 2. Histological section of the root canal after instrumental processing with manual $\mathrm{K}$-files at the distance of $3 \mathrm{~mm}$ from the apex (x40)

Maintaining the primary anatomy of the root canal curvature is ensured by the increased flexibility of the tool, which improves the safety of narrow curved canals and the rate of preparation. The design feature of the Silk files in the form of an elongated droplet eliminates the effect of screwing into the canal walls and permits to avoid dentin transportation and perforation. In addition, it is enough

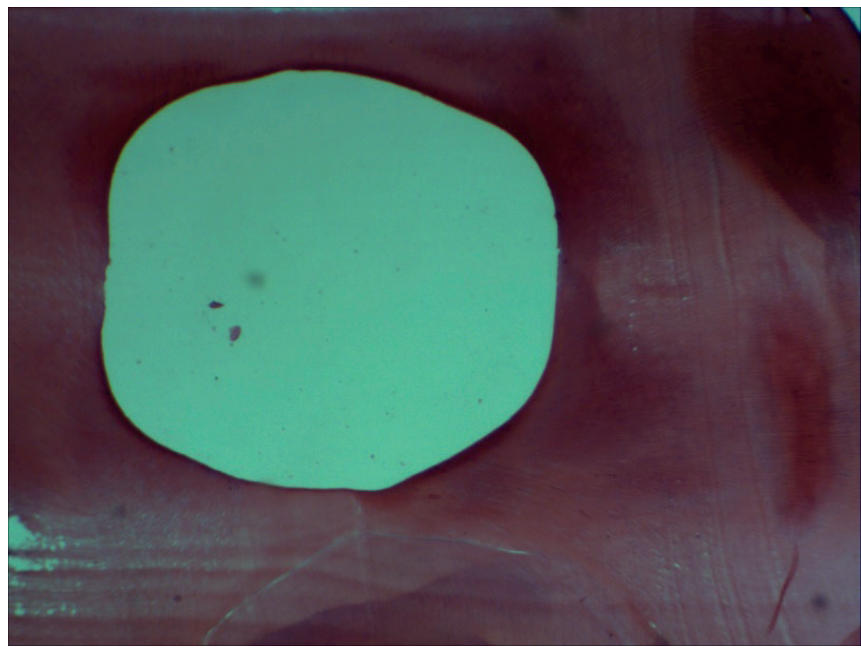

Fig. 4. Histological section of the root canal after preparation with Silkfiles at the distance of $3 \mathrm{~mm}$ from the apex (x100)

Table I. Root canals purity degree and the amount of predentine after preparation with various systems of endodontic instruments

\begin{tabular}{|c|c|c|c|c|c|c|}
\hline & \multicolumn{3}{|c|}{$3 \mathrm{~mm}$ from the apex } & \multicolumn{3}{|c|}{$5 \mathrm{~mm}$ from the apex } \\
\hline & $\begin{array}{c}\text { K-files } \\
n=15\end{array}$ & $\begin{array}{c}\text { Protaper } \\
n=15\end{array}$ & $\begin{array}{c}\text { Silk } \\
n=15\end{array}$ & $\begin{array}{l}\text { K-files } \\
n=15\end{array}$ & $\begin{array}{c}\text { Protaper } \\
n=15\end{array}$ & $\begin{array}{c}\text { Silk } \\
n=15\end{array}$ \\
\hline High degree & $3 / 20.0 \%$ & $4 / 26.7 \%$ & $7 / 46.7 \%$ & $4 / 26.7 \%$ & $6 / 40.0 \%$ & $9 / 60.0 \%$ \\
\hline Medium degree & $4 / 26.7 \%$ & $6 / 40.0 \%$ & $5 / 33.3 \%$ & $6 / 40.0 \%$ & $6 / 40.0 \%$ & $4 / 26.7 \%$ \\
\hline Low degree & $8 / 53.3 \%$ & $5 / 33.3 \%$ & $3 / 20.0 \%$ & $5 / 33.3 \%$ & $3 / 20.0 \%$ & $2 / 13.3 \%$ \\
\hline mount of predentin & $30 \%$ & $10 \%$ & $15 \%$ & $25 \%$ & 0 & 0 \\
\hline
\end{tabular}


to use three Silk files to form a root canal, versus 5-6 tools when working with manual files.

The Silk and Protaper Universal machine files showed a virtually equivalent result in the amount of sawdust and predentin removed at the distance of $5 \mathrm{~mm}$ from the apex. High and medium purity canals were detected in $86.7 \%$ (13/15) with Silk files and 80.0\% (12/15) with Protaper Universal files used. All predentin was removed at the distance of $5 \mathrm{~mm}$ from the apex when working with both groups of instruments.

In general, our results agree with the data obtained by other authors $[6,9]$. Understanding the morphology of dentin for preparation with different tool systems is of great practical importance. The design of all modern rotating nickel-titanium files involves the formation of a canal with a circular cross-section. Therefore, in the slit root canals untreated areas are left in small and large curvature, and in the premolars they are also found in the isthmus. Even if the root canal is shaped correctly, there may still be areas filled with sawdust and loose connective tissue inside it (fig. 3 ). The minimum number of untreated areas in the root canals remained when using Silk files, and the maximum number - when working with $\mathrm{K}$ files.

\section{CONCLUSION}

The machine type of preparation has considerable advantages over the methods of using hand tools. The smallest amount of sawdust in the apical area was found in the group of teeth treated with Silk files, then in the group treated with Protaper Universal machine files and with manual $\mathrm{K}$-files. The largest amount of predentin and dentin are removed by Protaper Universal files. Thus, it is appropriate to recommend Protaper Universal for root canal treatment in its upper and middle thirds, and Silk files - for apical area treatment, as well as for narrow and curved root canals.

Histological examination of the tooth root dentine with the combined application of instrumental and medical root canal system treatment is promising compared to the laser preparation.

\section{REFERENCES}

1. Lyakhova N., Kasinets S. The preexposure prophylaxis of stomatological diseases among the population of Ukraine in the practice of the family doctor and the pediatrician . Wiad. Lek. 2017;70(3):470-473.
2. Barylo 0., Kanishyna T., Shkilniak L. The effects of diabetes mellitus on patients' oral health. Wiad. Lek. 2018;71(5):1026-1031.

3. Peters 0., Boessler C., PaqueF. Root canal preparation with a novel nickeltitanium instrument evaluated with microcomputed tomography: canal surface preparation over time. J. Endod. 2010; 36 (6):1068-1072.

4. Solomonov M. Smazannyī sloö. Teoreticheskie vyikladki i prakticheskie rekomendatsii. Klinicheskaya endodontiya. 2009; III (3-4):60-61.

5. Gutmann Dj., Dumsha T., Lovdel P. Reshenie problem v endodontii. InMedpress-inform. Moskva: 2014, p. 166-206

6. Santarkanjelo F. Irrigatsiya v sovremennoĭ endodonii: ot standartnyih algoritmov do slojnyih sluchaev. Dental Times. 2011; 3 (10):1-13.

7. Gadzhula N.G., Fedyk T.V. Otsinka metodu tryvymirnoi obturatsii systemy korenevykh kanaliv pry likuvanni khronichnoho periodontytu [Evaluation of root canal three obturation technique in the treatment of chronic apical periodontitis]. Novyny stomatolohii. 2018;4(97):72-76. (In Ukrainian).

8. Kurtzman G. Positive versus negative pressure irrigation. Roots. 2012;3:16-22.

9. Ehsani Maryam. Sravnenie in vitro sposobnosti nikel-titanovyih rotatsionnyih instrumentov RaCe i Mtwo, a takje ruchnyih instrumentov K-Flexofile iz nerjaveyuschey stali ochischat kornevyie kanalyi. Endodonticheskaya praktika. 2010; 2(5):24-27.

The work is a fragment of the research project "Modern trends and latest technologies in the diagnosis and treatment of odontopathology, diseases of periodontal tissues and oral mucous membrane", state registration No. 0118 U005471.

\section{ORCID and contributorship:}

Maryna A. Goray - 0000-0003-4454-9161 ${ }^{B}$

Nataliia G. Gadzhula - 0000-0003-0016-2264 ${ }^{D}$

Larysa F. Kurdysh - 0000-0002-8259-9963 E,F

Olena V. Muntian - 0000-0002-9923-2957 C

Olena L. Cherepakha - 0000-0003-3629-4429 A

\section{Conflict of interest:}

The Authors declare no conflict of interest.

\section{CORRESPONDING AUTHOR Larysa F. Kurdysh}

56 Purohova str, 21018 Vinnytsia, Ukraine

tel: +380972936470

e-mail:klara075@gmail.com

Received: 10.03 .2020

Accepted: 07.05 .2020 